\title{
Etiopatogenia da ELA: causa única ou várias causas?
}

\section{ALS etiopathogeny: unique cause or multiple causes?}

\section{Helga Cristina Almeida da Silva}

Médica neurologista, Doutora, Professora afiliada e orientadora da Pós-graduação da UNIFESP. Rua Pedro de Toledo, 377. São Paulo - SP. Tel.: 5579-2668. e-mail: abrela99@ hotmail.com

\section{O sistema motor normal}

A realização de movimentos voluntários pressupõe a integridade anatômica e funcional do sistema nervoso e a interação harmoniosa dos vários sistemas relacionados ao movimento. De forma simplificada, o sistema motor voluntário se inicia no neurônio motor superior (primeiro neurônio ou cortical) localizado no córtex motor primário do giro précentral. Esses neurônios ligam-se por meio dos seus axônios (trato cortico-espinal ou piramidal) ao neurônio motor inferior (segundo neurônio) localizado nos núcleos motores do tronco encefálico ou na porção ventral da coluna cinzenta da medula espinal. A sinapse que une os dois neurônios motores tem o glutamato como neurotransmissor. Por sua vez, esses neurônios espinais fazem parte da unidade motora, onde cada neurônio liga-se por meio do seu axônio (raízes motoras e nervos motores) às fibras musculares por ele inervadas, em região especializada denominada junção neuromuscular, onde a acetilcolina é o mediador.

\section{Doença do neurônio motor}

Doença do neurônio motor (DNM) refere-se às doenças que afetam primariamente o neurônio motor (ou motoneurônio) superior e/ou inferior. O protótipo desse grupo é a esclerose lateral amiotrófica (ELA), doença degenerativa caracterizada pela perda progressiva de motoneurônios ao nível de medula espinal, tronco encefálico e córtex motor. O pico de incidência ocorre na sexta década, com ligeiro predomínio do sexo masculino. A maior parte dos casos é esporádica (somente uma pessoa afetada na família), mas 5 a 10\% correspondem à forma familiar. O quadro clínico é caracterizado por fraqueza e atrofia muscular progressivas e generalizadas, com evolução para paralisia de quatro membros, disfagia, 
disfonia, dispnéia. O óbito ocorre em média 3 anos após o início dos sintomas, por insuficiência respiratória.

Há formas de doença do neurônio motor que afetam primariamente os neurônios motores inferiores (atrofia muscular espinal - AME) ou os neurônios motores superiores (esclerose lateral primária - ELP) e que apresentam etiopatogenias específicas. No caso da AME, por exemplo, ocorre mutação no gene da sobrevivência do neurônio motor (SMN).

\section{O neurônio motor na ELA}

O estudo anatomopatológico mostra perda neuronal nas áreas motoras (giro pré-central, núcleos motores de nervos cranianos e corno anterior da medula espinal), gliose e esclerose do trato piramidal.

A análise dos neurônios sobreviventes mostra áreas de acúmulo anormal, como os corpos de Bunina, descritos em 1962, e os corpos de Lewy. Outras inclusões são formadas por agregados variados, compostos de ubiquitina, periferina, neurofilamentos ou superóxidodismutase (SOD).

\section{Genética na ELA}

A mutação da enzima SOD é rara em casos esporádicos de ELA (1\%), sendo encontrada em cerca de $20 \%$ dos casos familiares de ELA. Já foram descritas mais de 73 mutações no gene da SOD (www.alsod.org), havendo desde formas agressivas (evolução rápida de até 18 meses) até formas benignas (evolução lenta de até 18 anos).

Nos outros $80 \%$ de casos familiares, já foram descritas várias outras mutações (cromossomos 2, 9, 15, 16, 18, 20, X e DNA mitocondrial), mostrando que mesmo nos casos familiares de ELA há grande heterogeneidade genética e, seguramente, variados mecanismos etiopatogênicos.

Além disso, há evidências sugerindo que, mesmo quando se estuda um grupo com a mesma mutação, pode haver variação individual decorrente de fatores modificadores. Assim, o quadro clínico da ELA poderia ser modificado por alteração na expressão de outras substâncias, tais como neurofilamentos, VEGF (fator crescimento endotelial vascular), APEX (endonuclease apurínica/apirimídica - enzima reparadora de DNA), Apo E, CNTF (fator neurotrófico ciliar) e LIF.SOD. 
O acúmulo da enzima SOD resulta de mutações no gene que codifica a proteína SOD, situado no cromossomo 21. Essa proteína normalmente é responsável pela neutralização de radicais livres produzidos pelo metabolismo oxidativo neuronal. Assim, o defeito genético levaria à morte neuronal por perda da função normal da enzima SOD (ESTRESSE OXIDATIVO POR AÇÃO DOS RADICAIS LIVRES), mas também por ganho tóxico de função (PROTEÍNA SOD TÓXICA).

\section{Estresse oxidativo por ação dos radicais livres}

Normalmente a SOD age sobre o radical livre superoxido $\left(\mathrm{O}_{2}^{-}\right)$, produzindo água oxigenada $\left(\mathrm{H}_{2} \mathrm{O}_{2}\right)$, que sofrerá então a ação da catalase, para produção de água $\left(\mathrm{H}_{2} \mathrm{O}\right)$. Quando a SOD não atua de forma adequada, os radicais livres produzem estresse oxidativo e morte neuronal, com ativação da via da apoptose; os mecanismos envolvidos vão desde a lesão mitocondrial por peroxidação das membranas, até acúmulo de ubiquitinina e neurofilamentos por modificação protéica.

\section{Proteína sod tóxica}

A ação tóxica da SOD ocorreria por mecanismos diversos, tais como:

a) aumento de ligação da ubiquitinina (proteína que marca proteínas defeituosas destinadas à destruição) à proteína SOD defeituosa (ubiquitinação protéica), com formação de agregados intracelulares que prejudicam o metabolismo celular;

b) alteração de proteassomos (sistema responsável por destruição de proteínas anormais, entre elas a SOD mutada);

c) efeito amilóide (acúmulo de proteína insolúvel);

d) lesão secundária de mitocôndrias.

\section{ELA esporádica}

Os aspectos anatômicos e clínicos da ELA sofreram poucas modificações desde a descrição original por Charcot no século 19. Entretanto, o conhecimento sobre a causa da ELA e os mecanismos da doença tem se ampliado de forma impressionante, sem entretanto ter permitido ainda a total compreensão da ELA e a sua cura. 
Acredita-se que a ELA esporádica possua mecanismo etiopatogênico multifatorial, em função das múltiplas alterações encontradas nos modelos animais de DNM e em pacientes.

Entre as etiologias sugeridas, a principal é a excitoxidade pelo neurotransmissor glutamato. Mas também há evidências sugerindo participação da morte celular programada (apoptose), do acúmulo de neurofilamentos, da deficiência de fatores neurotróficos, de alterações da imunidade, de traumas físicos, de infecções virais persistentes (Poliovírus, Enterovírus, Retrovírus murino), do processo de envelhecimento com deficiência relativa de vitamina $\mathrm{E}$, e até mesmo de fatores ambientais químicos (como contato com inseticidas na lavoura) e físicos (radiações resultantes de explosões nucleares).

\section{Excitoxidade pelo glutamato}

Para o adequado funcionamento da sinapse glutamatérgica entre os motoneurônios superior e inferior, é preciso que o excesso de glutamato seja recaptado pelas células astrocíticas, por meio dos receptores GLT1 (transportador de glutamina específico da astroglia).

Evidências indiretas sobre a ação tóxica do glutamato sobre os motoneurônios provêm da DNM no Latirismo, onde a lesão está associada à ingestão de vegetais ricos em BOAA (ß $\mathrm{N}$ oxalyl amino L alanina), similar ao glutamato. Da mesma forma, estudos em modelos animais de DNM têm mostrado melhora da evolução com o uso de antagonista do receptor glutamatérgico não-NMDA do motoneurônio inferior.

Em pacientes com ELA há aumento dos níveis séricos e liquóricos de glutamato, além de diminuição da concentração tecidual - por diminuição de captação astrocítica. Finalmente, na ELA ocorre diminuição da concentração e inibição de receptores astrocíticos GLT1. O excesso de estímulo glutamatérgico leva ao aumento dos níveis intracelulares de cálcio, com conseqüente ativação de sistemas enzimáticos dependentes de cálcio (calpaínas, endonucleases, fosfolipases, proteinoquinase C, sintase do óxido nítrico), degradação proteica, peroxidação lipídica e morte celular por apoptose.

\section{Apoptose}

A apoptose do motoneurônio na ELA é a via final comum de múltiplos mecanismos etiopatogênicos, tais como menor atividade da SOD, ação tóxica da SOD mutada e aumento 
de radicais livres. A resultante clivagem do DNA desencadeia então a morte celular programada. Moléculas pró-apoptóticas (bax, caspases) estão aumentadas na ELA, bem como há diminuição de moléculas anti-apoptóticas (proto-oncogene $\mathrm{bcl}_{2}$ ).

\section{Neurofilamentos}

Neurofilamentos são vitais para o transporte bidirecional de organelas. O acúmulo de neurofilamentos pode ser uma lesão secundária, como a que ocorre após a axonotomia experimental. Por outro lado, existe um modelo animal de camundongo transgênico com DNM por mutação do gene que codifica os neurofilamentos de cadeia pesada (NFH). O acúmulo de neurofilamentos tem sido descrito na ELA esporádica, bem como em família com ELA por mutação do gene NFH, do cromossomo 11.

\section{Neurotrofinas}

Neurotrofinas são peptídeos expressos em várias regiões do sistema nervoso e que atuam por ligação a receptores específicos. Geralmente o seu nível está normal ou aumentado na ELA. Esse aumento pode ser decorrente da tentativa de preservar os neurônios sobreviventes. Entretanto, há um modelo animal de DNM associado à diminuição da produção de CNTF.

\section{Imunidade}

O papel da imunidade na ELA ainda é controvertido. Não se sabe, ainda, se a imunidade é um fator etiológico, fator de propagação ou simplesmente um epifenômeno.

$\mathrm{O}$ aumento da imunidade na ELA foi sugerido por evidências tais como a presença de infiltração de macrófagos e linfócitos nos locais de lesão, ativação de microglia e marcadores MHC-I e II / HLA-DR. Além disso, foram detectados anticorpos com ação antineuronal, anti canal de cálcio (L / P) e anti GM1, capazes, em estudos "in vitro", de aumentar a corrente de cálcio intracelular e provocar citoxicidade. A ELA tem sido associada a paraproteinemias, linfomas e tireoidopatias. Finalmente, há um modelo animal experimental de DNM autoimune.

Entretanto, até o momento, tentativas de inibir a imunidade na ELA não resultaram em cura da doença 


\section{Trauma}

Estudos clínicos mostram que a atividade física extenuante, como aquela dos trabalhadores braçais, é um fator de risco para a ELA.

Uma possível explicação para essa associação vem do exemplo do modelo animal de morte do neurônio motor resultante de axonotomia de ratos jovens; nesse caso, possivelmente a agressão ocorre em uma época da vida em que a ação protetora dos fatores neurotróficos ainda não é completa, resultando na morte do neurônio cujo axônio foi seccionado.

\section{Seletividade da lesão}

Além de conhecer a causa e o mecanismo da ELA, é importante saber porque a lesão é seletiva - para o sistema nervoso e para o neurônio motor.

A seletividade da lesão no sistema nervoso está relacionada à sua alta taxa oxidativa, à menor quantidade de sistemas anti-oxidativos e proteínas de ligação ao cálcio (calbindina, calmodulina, parvalbumina) e à propensão de acúmulo de íons metálicos.

A seletividade para a lesão do neurônio motor relaciona-se ao maior tamanho do seu pericário, à maior quantidade e extensão de dendritos - axônios - citoesqueleto (neurofilamentos), à concentração de colina acetil transferase e à menor quantidade de receptores para cálcio, andrógenos e neurotrofinas.

\section{Autosustentabilidade da lesão}

Outro ponto a considerar na etiopatogenia da ELA é a questão da continuidade da morte neuronal, com permanência da lesão após a agressão inicial.

Possivelmente, uma agressão inicial, como por exemplo o estresse oxidativo resultante da mutação da SOD, se propaga ao longo do tempo para um número cada vez maior de neurônios por meio da excitoxidade e se dissemina no espaço por meio dos mediadores liberados por cada neurônio que morre.

Por outro lado, se consideramos a excitoxidade como agressão inicial, é possível que essa agressão gere um círculo vicioso de aumento de cálcio intracelular, seguido de aumento de radicais livres com estresse oxidativo e finalmente lesão mitocondrial, que em conjunto levam à morte celular. 


\section{Lesão inicial}

A definição do tipo de agressão inicial e do local da lesão primária na ELA é difícil de precisar, visto que no momento do início dos sintomas clínicos já houve perda de $50 \%$ dos motoneurônios. Assim, como a agressão inicial ocorreu no passado, torna-se difícil a sua investigação precisa. Por esse motivo, também é discutível o local da lesão inicial: córtex motor, interneurônios, neurônio motor espinhal ou neuroglia.

A teoria cortico-motoneuronal postula que a ELA começa com a disfunção do neurônio motor superior e defeito da transmissão glutamatérgica. A teoria interneuronal sugere que a disfunção dos interneurônios não piramidais com ação inibitória poderia levar ao excesso de liberação de glutamato. Na teoria neuroglial, essas células poderiam iniciar o processo da morte do neurônio motor por mecanismos variados, como produção de substâncias tóxicas, diminuição de captação de glutamato ou diminuição de produção de neurotrofinas.

$\mathrm{Na}$ visão tradicional a ELA sempre foi considerada como doença somatocêntrica, ou seja, resultante de lesão primária do corpo (ou soma) do neurônio. Entretanto, novas evidências sugerem que alguns casos de DNM podem ser resultantes de lesão primária do axônio (doença axonocêntrica), com morte do neurônio secundária. Ainda, tanto em modelos animais de DNM como em pacientes com ELA, foi descrita perda precoce e seletiva na placa mioneural que precedeu as outras alterações.

O impacto das descobertas sobre a etiopatogenia da ELA é evidente ao se verificar o número crescente de estudos com novas drogas para essa doença. Cada vez mais prevalece a teoria de que a ELA é uma doença com muitas causas, assim cada paciente é único e o tratamento ideal seria feito com múltiplas medicações.

\section{Referências Bibliográficas}

1.Brown RH. Amyotrophic lateral sclerosis. Arch Neurol 1997; 54:1246-1250.

2.Cluskey S, Ramsden DB. Mechanisms of neurodegeneration in amyotrophic lateral sclerosis. J Clin Pathol: Mol Pathol 2001; 54:386-392.

3.Fischer LR, Culver DG, Tennant P, Davis AA, Wang M, Castellano-Sanchez A, et al. Amyotrophic lateral sclerosis is a distal axonopathy: evidence in mice and man. Exp Neurol 2004; 185(2):232-40.

4.Hand CK, Rouleau GA. Familial amyotrophic lateral sclerosis. Muscle Nerve 2002; 25:135-159. 
5.Hosler BA, Brown RH Jr. Copper/zinc superoxide dismutase mutations and free radical damage in amyotrophic lateral sclerosis. Adv Neurol 1995; 68:41-46.

6.Ihara Y, Mori A, Hayabara T, Kawai M, Namba R, Nobokuni K, et al. Superoxide dismutase and free radicals in sporadic amyotrophic lateral sclerosis: relationship to clinical data. J Neurol Sci 1995; 134:51-56.

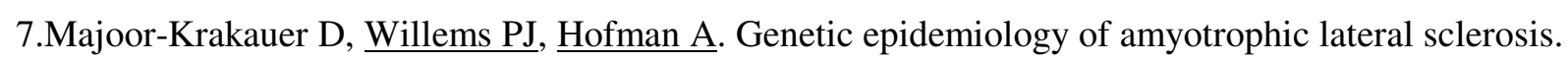
Clin Genet. 2003; 63(2):83-101.

8.Marx J. Mutant enzime provides new insights into the cause of ALS. Science 1996; 21:446-447.

9.Munsat TL, Andres MS, Finison L, Conlon MPH, Thibodeau PTA. The natural history of motoneuron loss in amyotropihc lateral sclerosis. Neurology 1988; 38:409-413.

10.Neilson S, Robison I, Rose FC. Mortality from motor neuron disease in Japan, 1950-1990: association with radioactive fallout from atmospheric weapons testing. J Neurol Sci 1995; 134:61-66. 11.Olanow CW, Arendash GW. Metal and free radicals in neurodegeneration. Current Opinion in Neurology 1994; 7:548-558.

12.Rouleau GA, Clark AW, Rooke K, Pramatarowa A, Krizus A, Suchowersky O, et al. SOD1 mutation is associated with accumulation of neurofilaments in amyotrophic lateral esclerosis. Ann Neurol 1996; 39:128-131.

13.Rowland LP. Amyotrophic lateral sclerosis: theories and therapies. Ann Neurol 1994;35:129-130.

14.Rowland LP. Amyotrophic lateral sclerosis. Cur Opin Neurol 1994; 7:310-315.

15.Serratrice GT, Munsat TL. Pathogenesis and therapy of amyotrophic lateral sclerosis. Advances in Neurology (vol 68). New York: Lippincott-Raven, 1995, p.1-290.

16.Silva HCA. Aplicabilidade da Biologia molecular: Doenças neurológicas. Biologia Molecular: guia prático e didático. Eça LPM (Org.). Rio de Janeiro: Revinter, 2004, p.216-222.

17.Swash M, Schwartz MS. What do we really know about amyotrophic lateral sclerosis? J Neurol Sci 1992; 113:4-16.

18.Urushitani M, Kurisu J, Tateno M, Hatakeyama S, Nakayama K, Kato S, Takahashi R CHIP promotes proteasomal degradation of familial ALS-linked mutant SOD1 by ubiquitinating Hsp/Hsc70. J Neurochem. 2004; 90(1):231-244.

19.Wiedau-Pazos M, Goto JJ, Rabizadeh S, Gralla EB, Roe JA, Lee MK, et al. Altered reactivity of superoxide dismutase in familial amyotrophic laterla sclerosis. Science 1996, 271:515-518.

20.Williams BD, Windebank AJ. Motor neuron disease. In Dick PJ and Thomas PK (eds.). Peripheral Neuropathy. Philadelphia: WB Saunders Company, Third edition, 1993, p.1028-1050. 